\title{
IFN- $\gamma$ action in the media of the great elastic arteries, a novel immunoprivileged site
}

\author{
Albert J. Dal Canto, ${ }^{1}$ Paul E. Swanson, ${ }^{1}$ Andrew K. O 'Guin, ${ }^{1}$ Samuel H. Speck, ${ }^{1,2}$ \\ and Herbert W. Virgin ${ }^{1,2}$ \\ 1D epartments of Pathology and Immunology, and \\ 2D epartment of M olecular M icrobiology, Washington University School of M edicine, St. Louis, M issouri, USA \\ Address correspondence to: Herbert W. Virgin IV, Washington University School of M edicine, 660 South Euclid Avenue, \\ St. Louis, M issouri 63110, USA. Phone: (314) 362-9223; Fax: (314) 362-4096; E-mail: virgin@immunology.wustl.edu.
}

Received for publication October 12, 2000, and accepted in revised form December 5, 2000.

Infection of medial smooth musclecells with $\gamma$-herpesvirus 68 ( $\gamma \mathrm{HV} 68$ ) causes severe chronic vasculitis that is restricted to the great el astic arteries. We show herethat persistence of disease in the great elastic arteries is (a) due to inefficient clearance of viral infection from this sitecompared with other organs or other vascular sites, and (b) associated with failureof $\mathrm{T}$ cells and macrophages to enter the virus-infected elastic media. Thesefindings demonstrateimmunoprivilege of the media of the great elastic arteries. Wefound that IFN - $\gamma$ acted on somatic cells during acuteinfection to prevent the establishment of medial infection and on hematopoietic cells to determinetheseverity of disease in this site. Theimmunoprivileged elastic media may provide a site for persistence of pathogens or self antigens leading to chronic vascular disease, a process regulated by IFN- $\gamma$ actions on both somatic and hematopoietic cells. These concepts have significant implications for understanding immune responses contributing to or controlling chronic inflammatory diseases of thegreat vessels.

J. Clin. Invest. 107:R15-R22 (2001).

\section{Introduction}

We developed a new animal model of chronic viral vasculitis restricted to the great elastic arteries (chronic elastic arteritis; refs. 1 and 2). Severe chronic elastic arteritis persists weeks to months after infection of IFN - $\gamma$ receptor-deficient (IFN- $\gamma \mathrm{R}^{-1-}$ ) mice with doses of the $\gamma$-herpesvirus $\gamma \mathrm{HV} 68$ that fail to inducearteritis in wild-typemice. Infection with $\mathrm{\gamma HV68}$ also increases vascular lesion formation in apoE-deficient animals (3). The role of IFN - $\gamma$ in regulating $\gamma \mathrm{H}$ V68 arteritis is particularly interesting since IF $\mathrm{N}-\gamma$ is a key regulator of vascular inflammation in multiple systems and can either increase or decrease vascular pathology, depending on the nature of theinsult to the vessel $(1,4-6$, reviewed in ref. 7).

$\gamma H$ V68-induced chronic elastic arteritis is characterized by striking inflammation of the adventitia and intima of the affected artery segment in regions containing productively infected smooth musclecells (SM Cs) in themedia $(1,2)$. Continued productive infection contributes to chronic damage and inflammation (2). Interestingly, while immunodeficiency makes mice more susceptible to chronic elastic arteritis, $\gamma \mathrm{H}$ V68-infected wild-type weanling micealso develop elastic arteritis lasting up to 5 months after infection (1). This raises the question of why infection of the great vessel s can persist for prolonged periods in an immunocompetent host.

In this study, we show that the tropism of $\gamma \mathrm{HV} 68$ for the media of the elastic arteries during chronic infection was due to failure of the immune response to effectively clear the virus from theelastic media despite effective clearance of other vascular sites and other organs. Effector $T$ cells and macrophages did not enter the media of the great vessels even when active viral infection was present. We also show that IFN- $\gamma$ independently regu- lates theseverity and incidence of arteritis by actions on different cell types. These studies defining an immunoprivileged site within the vasculature, and demonstrating the cellular basis for a critical protective role of IFN $-\gamma$ in this site, have important implications for understanding chronic inflammatory diseases of thegreat vessels.

\section{Methods}

Viruses, mice, and pathologic analysis. $\gamma \mathrm{HV} 68$ was passaged and assayed as described (1). $\quad$ HV68 mutants M 1.LacZ and V-cyclin.LacZ have been described $(8,9)$. IFN $-\gamma \mathrm{R}^{-1-}$ miceareon a pure $129 \mathrm{Ev} / \mathrm{Sv}$ background, and $129 \mathrm{Ev} / \mathrm{Sv}$ controls were used as controls (10). M ice 5 to 7 weeks old were infected intraperitoneally with $\gamma \mathrm{HV} 68$ in $0.5 \mathrm{ml}$ of complete DMEM for all experiments. Organs were titered by plaque assay, and prepared and stained for histopathologic examination as described (1). Criterion for lesion scores based on hematoxylin and eosin $(\mathrm{H} \& \mathrm{E})$ histology were as described (2). Briefly, scores increased from 0 to 5 as the extent of adventitial and intimal thickening, neutrophilic infiltration, and medial necrosis increased. Lesions were scored in a blinded fashion by A.J. Dal Canto and H.W. Virgin, and scores were averaged. Microscopic images were prepared using a Zeiss Axi ophot microscope with a Spot camera and Spot software 1.1 (Diagnostics Instruments, Sterling Heights, Michigan, USA) and Northern Eclipse v2.0 software (Empix Imaging Inc., Mississauga, O ntario, Canada). 
$\beta$-galactosidasestaining and immunohistochemistry. Mice were infected intraperitoneally with $5 \times 10^{6} \mathrm{PFU}$ M 1.LacZ or $\gamma$ HV68 V-cyclin.LacZ and sacrificed by perfusion with $30 \mathrm{ml} 2 \%$ paraformaldehyde and $0.2 \%$ glutaraldehyde in PBS. The heart, aorta, and visceral organs were removed en bloc, rinsed in PBS, and stained for $\beta$ galactosidase ( $\beta$-gal) activity at $37^{\circ} \mathrm{C}$ overnight (11), before fixation in $4 \%$ paraformaldehyde. Staining was evaluated under a dissecting microscope, and pictures were taken with a Kodak DC120 digital camera. Viral antigen was detected by immunohistochemistry as described (1). For detection of inflammatory cells, frozen sections were fixed in 1:1 methanol/acetone at $-20^{\circ} \mathrm{C}$. Endogenous peroxidase activity was inhibited (1), slides wereblocked ( $1 \% \mathrm{BSA}, 0.2 \%$ powdered skim milk, $0.3 \%$ triton in PBS) for 30 minutes, and then biotin blocked (Vector Laboratories, Burlingame, California, USA). Rat mAb's used were: anti-CD 4 Ab GK 1.5 (12); anti-CD 8 Ab H 35 (12), anti-B-220 Ab 14.8 (12), and anti-CD 11b Ab 5C6 (CRL-1969; American Type Culture Collection, Rockville, M aryland, USA), and were added at $25 \mathrm{ng} / \mathrm{ml}$ overnight at $4^{\circ} \mathrm{C}$. F $4 / 80$ (13) mAb supernatant was used at a 1:2000 dilution. Rat IgG was used as a negative control. Staining was detected using $\mathrm{F}\left(\mathrm{ab}{ }^{\prime}\right)_{2}$ biotin-conjugated donkey anti-rat secondary $A b$ $(1.2 \mu \mathrm{g} / \mathrm{ml}$; Jackson ImmunoResearch Laboratories Inc., West Grove, Pennsylvania, USA).

Bone marrow reconstitutionsand IFN- $\gamma$ depletion in vivo. Four-week-old mice were lethally $\gamma$-irradiated with $1100 \mathrm{R}$ followed by intraven ous injection of 1 to $2 \times 10^{7}$ nucleated bonemarrow cells from sex-matched $129 \mathrm{Ev} / \mathrm{Sv}$ or IFN$\gamma \mathrm{R}^{-/-}$mice. The percentage of reconstitution was assessed at 6-8 weeks using quantitativeSouthern blots of peripheral blood lymphocyte D N A (QIAamp blood kit; QIAGEN Inc., Val encia, California, USA) cut with BamH 1 and probed with a 2-kb fragment corre sponding to exon 4 of theIFN $-\gamma \mathrm{R}$ gene (14). To transiently depleteIFN $-\gamma$, mice were injected intraperitoneally with $250 \mu \mathrm{g}$ of IFN $-\gamma$-neutralizing hamster $\mathrm{mAb} \mathrm{H} 22$ (15) in $0.5 \mathrm{ml}$ sterilesaline 1 day before and 6 days after infection. To chronically deplete IFN $-\gamma$, mice were injected weekly until sacrifice (6 weeks). The Ab dose was selected based on previous reports of effective IFN- $\gamma$ depletion with $\mathrm{H} 22(15,16)$.

Primary cell cultures. Primary mouse aortic cells wereprepared based on published protocols $(17,18)$. Ten thoracic aortas from 4- to 6-week-old male $129 \mathrm{Ev} / \mathrm{Sv}$ micewereharvested, placed in HBSS with $0.2 \mathrm{mM} \mathrm{CaCl}(\mathrm{HBSS} / \mathrm{Ca})$, and theadventitiaremoved by blunt dissection. Digestion with collagenase followed by trypsin yielded an intimal/adventitial culture. Further digestion with collagenase, elastase, and trypsin yielded a medial culture. After 3-4 days, cells were treated with $0.12 \%$ trypsin plus $0.5 \mathrm{mM}$ EDTA for $5 \mathrm{~min}$ utes at $37^{\circ} \mathrm{C}$ and replated. Every $2-4$ days thereafter, each well was passaged into two new wells. Cells $\left(5\right.$ to $\left.50 \times 10^{4}\right)$ were obtained from each culture after the second passage and plated ( 1 to $3 x$ $10^{4}$ cells) into eight-well glass chamber slides (LabTek; NalgeN unc International, N aperville, Illinois, USA) for use in immunofluorescence studies, 24-well tissueculture(TC) plates for phase-contrast microscopy, or 12-well TC plates for electron microscopy (EM). Two to three days later cultures were treated for 48 hours with or without IFN- $\gamma(250$ $\mathrm{U} / \mathrm{ml}$ for medial cultures and $64 \mathrm{U} / \mathrm{ml}$ for intimal/adventitial cultures; Genzyme Pharmaceuticals, Cambridge, M assachusetts, USA), infected at an moi of 5 for 2 hours at $37^{\circ} \mathrm{C}$, and then cultured in fresh medium with or without IFN- $\gamma$. Fresh media with or without IFN$\gamma$ was added every 3 days. Phase-contrast pictures were taken on a Olympus CK2 microscope equipped with a Kodak DC120 digital camera and the Kodak MDS 120 v1.0 acquisition program.

Immunofluorescence and EM. For immunofluorescence, cells were fixed for 20 minutes at $-20^{\circ} \mathrm{C}$ in methanol, washed, and then blocked for $30 \mathrm{~min}$ utes at room temperature in $20 \mu \mathrm{g} / \mathrm{ml}$ BSA, $20 \%$ goat serum, $0.01 \%$ triton in PBS. Polyclonal anti- $\gamma \mathrm{H}$ V68 antiserum (1), or preimmuneserum, was used at a dilution of 1:500 to detect viral antigen. A mouse mAb to human muscle actin (HHF35; DAKO Corp., Carpinteria, California, USA) was used at $0.55 \mu \mathrm{g} / \mathrm{ml}$ to detect SM Cs. An isotypematched Ab to keyholelimpet hemocyanin was used as a negative control (PharMingen, San
Diego, California, USA). Primary Ab's were incubated overnight at $4^{\circ} \mathrm{C}$, and secondary $A b$ 's wereadded for 1 hour at room temperature. Muscle actin was detected using a Cy3-conjugated goat anti-mouse secondary antibody (10 $\mu \mathrm{g} / \mathrm{ml}$; Jackson Immuno Research Laboratories Inc.), and viral antigen was detected using an Oregon green 488-conjugated goat anti-rabbit secondary antibody $(7 \mu \mathrm{g} / \mathrm{ml}$; M olecular Probes, Eugene, Oregon, USA). Bisbenzimide was added $(0.5 \mu \mathrm{g} / \mathrm{ml})$ to stain thenuclei blue. For EM, cells werefixed with $3 \%$ glutaraldehydein $0.1 \mathrm{M}$ cacodylate buffer $(0.1 \mathrm{M}$ sodium cacodylate in water, $\mathrm{pH} 7.0$, plus $0.54 \%$ wt/vol dextrose) for 1 hour, washed in $0.1 \mathrm{M}$ cacodylatebuffer, scraped, pelleted, and processed as described (2). SM Cs were distinguished by thepresence of organized actin filaments, subplasmalemmal attachment plaques, and pinocytosis. The presence of viral capsids was evaluated within nuclei in a blinded fashion by A.J. Dal Canto on high-power photographs $(\times 57,800)$.

Statistical analysis. D ata were plotted and statistically analyzed using GraphPad Prism (GraphPad Software, San Diego, California, USA). The severity of pathology was statistically analyzed by comparing lesions scores using the $M$ ann-Whitney test. Staining of different regions of the aorta for $\beta$-gal and alterations in incidence of arteritis in mice treated with anti-IFN - $\gamma$ Ab were compared using a $\chi$-square test and Fisher's exact test (which gave comparable results). D ata from immun ofluorescence and EM studies were analyzed using an unpaired t test.

\section{Results}

Viral tropism due to anatomic specificity of immune function. We considered two hypotheses to explain the restriction of $\gamma \mathrm{H} \mathrm{V68-induced} \mathrm{arteritis} \mathrm{to} \mathrm{the} \mathrm{great}$ vessels. $\gamma \mathrm{H}$ V 68 might infect only SM Cs of the elastic media, leaving other vascular sites uninfected. Alternatively, $\gamma \mathrm{HV} 68$ could infect multiple vascular sites, but be efficiently cleared from all sites other than the elastic media. To distinguish between thesehypotheses, we infected IFN- $\gamma \mathrm{R}^{-/-}$mice with $\beta$ galactosidase ( $\beta$-gal) expressing $\gamma \mathrm{H}$ V68 mutants that induce chronic elastic arteritis $(8,9)$. At various times, the 



aorta with its major branches and attached heart, liver, and kidneys were dissected out as a unit and stained for $\beta$-gal activity to localizeregions of viral infection (Figure 1 and 2).

Seven to fifteen days after infection, $\gamma \mathrm{HV} 68$ was present in both the media and adventitia of the great vessels as shown by evaluation under the dissecting microscope (Figure $1 \mathrm{~b}$ and Figure 2, regions $a$ and $b$ ). Together with infection of a peripheral vessel adjacent to the kidney (Figure la and Figure 2 , region $\mathrm{c}$ ), this proves that $\gamma \mathrm{HV} 68$
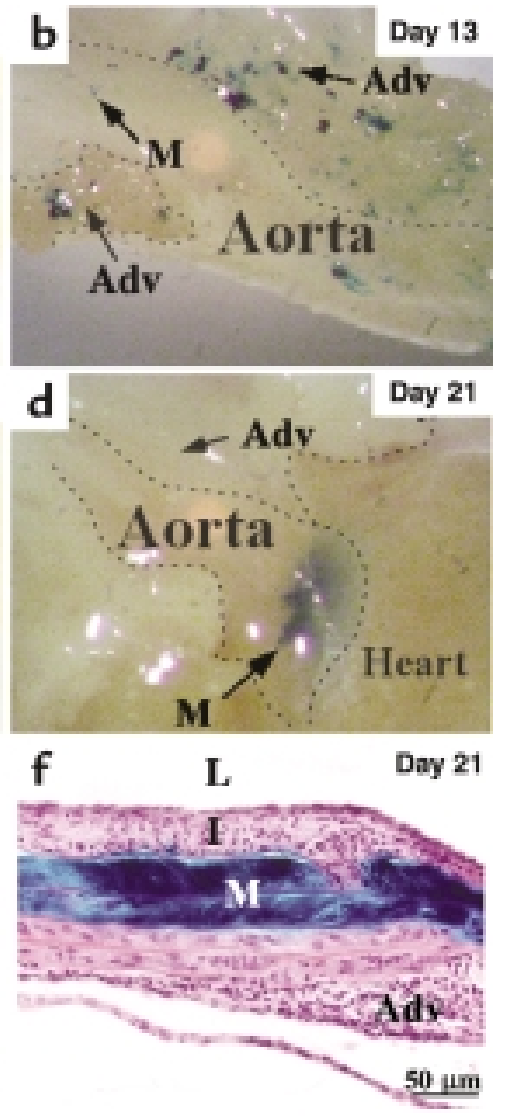

tropism is not due to selective infection of SM C s in the elastic media.

Infection with $\gamma \mathrm{H}$ V68 was efficiently cleared from both the adventitia of the great vessels and a peripheral vessel. Whereas 20 of 28 mice had bilateral staining of a peripheral vessel 7-15 days after infection (Figure $1 a$ and Figure 2, region c), clearance was evident 17-21 days after infection and complete by $42-43$ days $(P<0.0001$ for latetimes versus days 7-15). Similarly, between 17 and 21 days after infection, adventitial staining was cleared signif-

\section{Figure 1}

Localization of $\gamma \mathrm{H}$ V68 vascular infection over time. IFN $\gamma \mathrm{R}^{-1-}$ mice were infected with either M 1.LacZ or yHV68 v-cyclin.LacZ. The aorta and its major branches were resected and stained en bloc for $\beta$ gal activity. Infection with wild type $\gamma H \mathrm{H} 68$ resulted in no comparable staining.

(a) Staining 13 days after infection of a vessel on the posterior surface of the kidney. (b) Staining 13 days after infection of the descending aorta. N ote staining in both the adventitia (Adv) and media (M). (c) Staining 21 days after infection of the descending aorta. Staining is predominately in the media. (d) Staining 21 days after infection at the base of the aorta. Note staining is only in the media. (e) Cross section from the descending aorta 21 days after infection demonstrating inflammation surrounding medial staining. (f) High-power view of boxed region in e. L, lumen; I, intima.

icantly (Figure $1 \mathrm{~b}$ compared to Figure $1, c$ and $d$, and Figure 2, regions $a$ and $b ; P<0.0001$ for latetimes versus days 7-15). In contrast, infection of the elastic media at the base of the aorta persisted through days 42-43. In other studies, persistence of medial infection and disease of the great vessels has been seen up to 105 days after infection (1). Clearance of the media of the thoracic aorta also lagged behind clearance of either the adventitia or a peripheral vessel (Figure 1 and 2).

Clearance of adventitial infection was immune mediated because it did not occur in B cell- and T cell-deficient RAG 1 ${ }^{-1-}$ mice (not shown). Failure of efficient immune clearance of $\gamma \mathrm{HV} 68$ from the elastic media was associated with a lack of infiltration of CD 4 T cells (not shown), CD 8 T cells, and macrophages into the media (Fig-

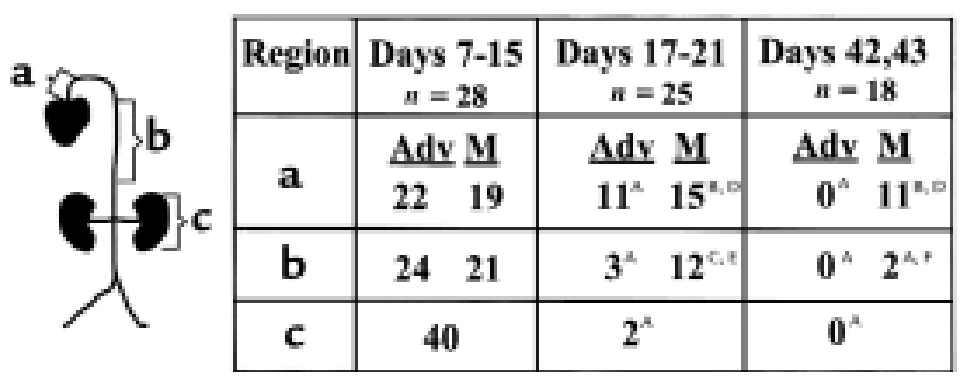

\section{Figure 2}

Q uantitation of clearance of $\gamma \mathrm{HV} 68$ from different vascular structures over time. IFN - $\gamma \mathrm{R}^{-1-}$ mice were infected and analyzed as in Figure 1 at days 7, 9, 11, $13,15,17,19,21,42$, and 43 after infection. $n$, number of mice. The number of aortas with blue staining in the adventitia (Adv) or media (M) is reported for the aortic base (a) or the descending aorta (b), which was representative of the entire aorta. Staining of a peripheral vessel on the posterior surface of both kidneys is also reported (c). For staining at late times compared with staining at days $7-15$, AP $<0.0001$; $B P>0.05$; $C P=0.04$. For medial clearance compared with adventitial clearance, $\mathrm{DP}<0.0001$; $\mathrm{EP}=0.006$; $\mathrm{FP}=0.1$. 

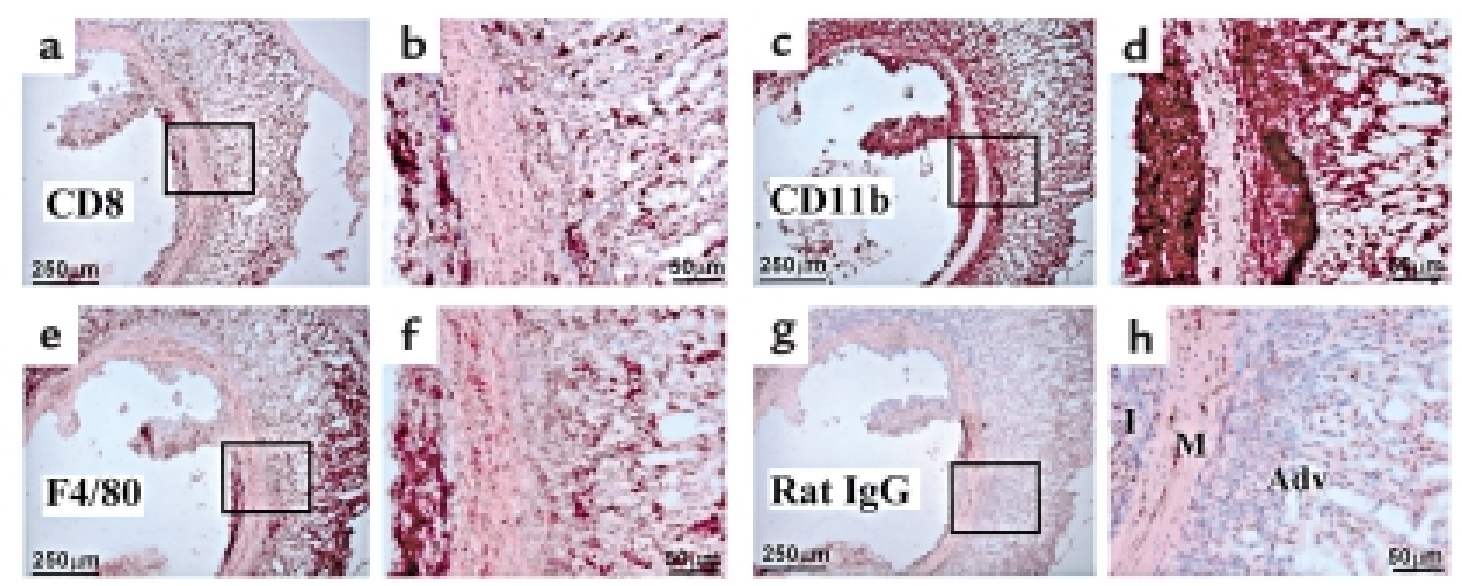

\section{Figure 3}

Localization of inflammatory cells in arteritic lesions. Shown are low- and high-power views of immunohistochemistry on parallel aortic frozen sections from an IFN- $\gamma \mathrm{R}^{-1-}$ mouse infected with $\gamma \mathrm{H}$ V68 4 weeks after infection. Dark-brown staining represents Ab binding. (a and b) CD8 T cells are present in the intima and adventitia, but not the media. Similar staining was observed with an Ab to CD4 (not shown). (c and d) Staining for CD11b shows M ac1-positive cells (macrophages and neutrophils) in all threelayers of the aorta. (eand f) Staining for F4/80-positive macrophages is limited to the intima and adventitia. ( $\mathbf{g}$ and $\mathbf{h}$ ) Negative control with rat IgG. The area of highest background staining is shown in $\mathbf{h}$ for comparison with specific staining in panels $\mathbf{b}, \mathbf{d}$, and $\mathbf{f}$. I, intima; $\mathbf{M}$, media; Adv, adventitia.

ure 1, eand f, and Figure3) despitethe presence of active virus infection of medial smooth muscle cells (refs. 1 and 2), data not shown, and Figure 1f). The only inflammatory cells consistently present in the media were CD 11b-positive (M acl-positive) cells with the morphology of neutrophils (Figure 3, $c$ and d).

Failure to clear the elastic media in normal mice. While it was possible that IFN- $\gamma$ was required for effective immunefunction in the elastic media, wehypothesized that inefficient clearance of medial infection reflected a fundamental property of the elastic media. This hypothesis makes two pre dictions: (a) it should be possible to induce chronic el astic arteritis in wildtypemice, which havefunctional IFN$\gamma$ responses, with viral doses high enough to establish medial infection; and (b) transient depletion of IFN - $\gamma$ in wild-type mice during acute infection should induce chronic elastic arteritis by fostering medial infection.

Consistent with our hypothesis, increasing the dose of $\gamma \mathrm{HV} 68$ in wildtype mice to greater than $5 \times 10^{7} \mathrm{PFU}$ $\gamma \mathrm{H}$ V68 resulted in arteritis persisting 5.5 to 10 weeks (Figure 4). In contrast, IFN- $\gamma \mathrm{R}^{-1-}$ mice developed chronic arteritis when infected with 50 -fold less virus (106 PFU) (1). Whilearteritis persisted, none of the ten wild-type animals evaluated at 6 weeks had detectable $\gamma \mathrm{HV} 68$ in spleen, liver, or lung (sensitivity of plaque assay 50 PFU/organ), demonstrating that persistence occurs in the great vessels despite clearance of other organs. Furthermore, transient depletion of IFN - $\gamma$ increased susceptibility of wild-type mice to chronic arteritis. Seventeen percent ( 5 of 29) of control miceinfected with $5 \times 10^{7} \mathrm{PFU}$ of $\gamma \mathrm{HV} 68 \mathrm{had}$ chronic elastic arteritis 6 weeks after infection. In contrast, $67 \%$ (6 of 9) of mice transiently depleted of IFN- $\gamma$ developed chronic disease (Figure 4a; $P$ $=0.0043$ ). At twofold to fivefold lower infectious doses, disease was seen in $50 \%$ of transiently depleted mice, but not in controls (Figure 4a; $P=0.0062$ ).

Wescored theseverity of lesions after $\gamma \mathrm{HV} 68$ infection of wild-type mice, wild-type mice transiently or chronically depleted of IFN $-\gamma$, and IFN $-\gamma \mathrm{R}^{-1-}$ mice(Figure 4, b-e). All arteritic lesions had viral antigen detectable in the media by immunohistochemistry (not shown and ref. 1 and 2). Wild-typeand transiently IFN- $\gamma$-depleted wild-type mice had mild lesions with mononuclear infiltrates in the aortic intima and/or adventitia, but no medial neutrophilic infiltrates or necrosis (Figure $4, \mathrm{~b}$ and $\mathrm{c}$ ). In contrast, IFN $-\gamma \mathrm{R}^{-/-}$and chronically IFN- $\gamma$-depleted wild-type mice had severe lesions with intense medial neutrophilic infiltrates and/or medial necrosis (Figure 4, $d$ and e).
Cellular sites of IFN - $\gamma$ action that determine incidence and severity of arteritic lesions. We performed reciprocal bone marrow transfers to identify the cellular sites of IFN- $\gamma$ action that determine the incidence and severity of chronic elastic arteritis. Wild-type (129Ev/Sv) and IFN $-\mathrm{R}^{-1-}$ recipient mice were lethally irradiated and reconstituted with bone marrow cells from either $129 \mathrm{Ev} / \mathrm{Sv}$ or IFN $-\gamma \mathrm{R}^{-/-}$donors (donor $\rightarrow$ recipient: $129 \mathrm{Ev} / \mathrm{Sv} \rightarrow 129 \mathrm{Ev} / \mathrm{Sv}$; IFN- $-\mathrm{R}^{-1-} \rightarrow$ IFN- $\gamma \mathrm{R}^{-1-} ; 129 \mathrm{Ev} / \mathrm{SV} \rightarrow$ IFN $-\gamma R^{-1-} ;$ IFN $-\gamma R^{-1-} \rightarrow 129 \mathrm{Ev} / \mathrm{Sv}$ ). After 8 weeks, reconstituted mice wereinfected with $10^{7} \mathrm{PFU}$ of $\gamma \mathrm{HV} 68$, and arteritis was evaluated over 12 weeks. Controls demonstrated that the procedure neither protected from, nor predisposed to, arteritis. Thus, 10 of 13 of theIFN $\gamma \mathrm{R}^{-/-} \rightarrow \mathrm{IFN}-\gamma \mathrm{R}^{-/-}$mice developed severe arteritis, whereas 0 of 11 of the $129 \mathrm{Ev} / \mathrm{Sv} \rightarrow 129 \mathrm{Ev} / \mathrm{Sv}$ mice developed lesions (Figure 5, groups $A$ and D). The IFN- $\gamma$-receptor status of the recipient determined susceptibility to arteritis since 9 of 18 of the $129 \mathrm{Ev} / \mathrm{Sv} \rightarrow$ IFN $\gamma \mathrm{R}^{-1-}$ mice, but 0 of 19 of the IFN $-\gamma \mathrm{R}^{-/-}$ $\rightarrow 129 \mathrm{Ev} / \mathrm{Sv}$ mice developed disease (Figure 5 , groups $B$ and $C$ ). Lesions in IFN $-\gamma \mathrm{R}^{-/-} \rightarrow$ IFN $-\gamma \mathrm{R}^{-1-}$ mice were very severe (Figure 5, group $A$; average lesions score $4.7 \pm 0.3$ ), while lesions in the $129 \mathrm{Ev} / \mathrm{Sv} \rightarrow \mathrm{IFN}-\gamma \mathrm{R}^{-/-}$mice were much less severe, lacking medial neutrophilic infiltrates and necrosis (Figure 
5, group B; average lesion score $1.7 \pm$ 0.2 ). Thus, the presence of IFN- $\gamma$ receptor on hematopoietic cells determined lesion severity even when somatic cells lack the IFN- $\gamma$ receptor.

IFN- $\gamma$ blocks $\gamma \mathrm{H}$ V68 infection and replication in SM Cs and non-SM Cs from the aorta. Since $\gamma H$ V 68 replicates in vascular SM Cs within arteritic lesions $(1,2)$ and IFN $-\gamma$ prevents arteritis, we tested the hypothesis that IFN $-\gamma$ has antiviral effects in primary aortic cells. SMCs and non-SMCs isolated from mouse aortas were treated with IFN - $\gamma$ for 48 hours and then infected with $\gamma \mathrm{HV} 68$. IFN- $\gamma$ reduced virus induced cytopathic effect (Figure 6, $a$ and b). Using duallabel immunofluorescence, we found that IFN $-\gamma$ decreased the percentage of both non-SM Cs and SM Cs expressing viral antigen $(P<0.005$; Figure $6, c, d$, and g). IFN - $\gamma$ treatment significantly decreased the percentage of cells with intranuclear viral capsids as determined by EM (Figure 6, e, f, and $g$ ). Thus IFN- $\gamma$ has antiviral effects in both SMCs and other primary cells derived from the aorta.

\section{Discussion}

We found that the immune system functions less efficiently in the elastic media of the great vessels than in small vessels, the adventitia of the great vessels, or visceral organs such as spleen, liver, and lung. For this reason the immunesystem, rather than viral interactions with cellular receptors, determines tropism of $\gamma \mathrm{HV} 68$ for the great elastic arteries during chronic disease. These findings make the important point that chronic diseases of thegreat vessels may be dueto immunoprivilege of the elastic media, resulting in persistence of pathogens or antigens in this site, in turn leading to chronic inflammation. Lack of effective immune clearance was independent of IFN $-\gamma$, although IFN $-\gamma$ prevented the establishment of medial infection and regulated the severity of disease once infection was established. This essential protective role of IFN $-\gamma$ contrasts with studies emphasizing promotion of vascular pathology by IFN - $\gamma$ (reviewed in ref. 7), underscoring the fact that the natureof the vascular insult determines whether specific immunefunctions are helpful or harmful.
While many mechanisms could explain immunoprivilege within the vasculature, the failure of T cells and macrophages to enter theelastic media suggests one potential mechanism: limited access of effector cells. Lack of immunecell access to theelastic media may bea general contributor to chronic vascular disease and is seen in other circumstances. For example, injection of mice with splenocytes stimulated in vitro with syngeneic microvascular SM Cs resulted in medial and adventitial infiltrates in arterioles and venules, but not in elastic arteries (19). Interestingly, murine cytomegalovirus (M CM V) also induces chronic elastic arteritis with alack of medial infiltrates


\section{Figure 4}

Incidence and severity of chronic elastic arteritis in wild-type mice infected with high doses of $\gamma \mathrm{HV} 68$ with or without transient depletion of IFN $-\gamma$. Mice were infected with the indicated doses of $\gamma \mathrm{H} \mathrm{V} 68$ with or without depletion of IFN- $\gamma$ and evaluated for arteritis on H\&E-stained sections 5.5 to 10 weeks after infection. (a) The incidence of arteritis in various groups is presented. Seven of 19 mice infected with 17 to $20 \times 10^{7}$ PFU $\gamma H$ V68 died within 7 days. Twelve of 14 mice infected with 34 to $50 \times 10^{7}$ PFU died within 7 days. Data for transient depletions are from two independent experiments. Data for no depletions are from 4-5 independent experiments. AP $=0.0062$; $B P=0.0043$. (b) Lesion at the aortic base of a $129 \mathrm{Ev} / \mathrm{Sv}$ mouse sacrificed 10 weeks after infection with $10^{8} \mathrm{PFU} \gamma \mathrm{H}$ V68. Lesions in transiently IFN $-\gamma$-depleted $129 \mathrm{Ev} / \mathrm{Sv}$ mice have similar histology (lesion scores for 25 mice from both groups combined $=2.0 \pm 0.2 ; P<0.0001$ for scores compared with IFN- $\gamma R^{-1-}$ mice, $P=0.001$ compared with chronically depleted wild-type mice). (c) High-power view of boxed region in $\mathbf{b}$. (d) Lesion at the aortic base of a chronically IFN- $\gamma$-depleted 129Ev/ Sv mouse sacrificed 6 weeks after infection with $5 \times 10^{7} \mathrm{PFU} \gamma \mathrm{HV} 68$ (lesion scores for four mice $=4.0 \pm 0.7$ ). Arteritis in IFN $-\gamma \mathrm{R}^{-1-}$ mice has similar histology (lesion scores for 16 mice $=5.0 \pm 0$ ). (e) High-power view of boxed region in $\mathbf{d}$. The black lines show the boundaries of the media. Adv, adventitia; M, media; I, intima; L, lumen; $V$, aortic valve. ND, not determined. 


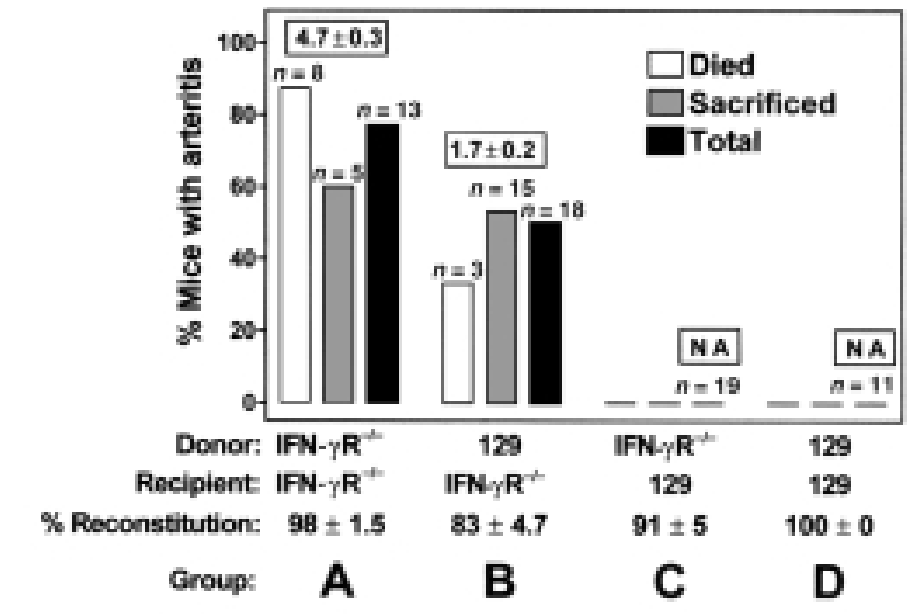

Figure 5

IFN- $\gamma$ prevents chronic elastic arteritis by effects on somatic cells but regulates the nature of the pathology by effects on hematopoietic cells. Reciprocal bone marrow reconstitutions were performed between IFN- $\gamma \mathrm{R}^{-/-}$and $129 \mathrm{Ev} / \mathrm{Sv}$ mice, and arteritis was evaluated for 12 weeks after $\gamma \mathrm{HV} 68$ infection. Numbers above bars represent the number of mice within a group. Boxed numbers represent average lesion scores for a group. Data are pooled from four independent experiments. For incidence of disease, $P=0.0001$ comparing group $A$ with $D$, and $P=0.0004$ comparing group $B$ with $C$. For severity of disease, $P<0.0001$ comparing groups $A$ and $B$. NA, lesion scores not applicable.

despite the presence of viral antigen in the media (6). Similarly, viral persistencein thekidney may be dueto limited entry of CD 8 lymphocytes into the kidney despite its rich vascular supply $(20,21)$. Thus, the failure of immune cells to enter certain anatomic sites may be a significant contributor to immunoprivilege. Perhaps medial elastic laminae, especially in thoseportions of themedia not penetrated by thevasa vasorum, provide a significant barrier to entry of lymphocytes and macrophages. The process of immune cell entry into the media could be regulated also by cytokines (for example IFN $\gamma$ ) by induction of cell adhesion molecules or proteases critical for tissue penetration $(22,23)$.

Onepotential problem with extending observations in the mouse system to the situation in human arteries is thelack of vasa vasorum in mice. $\mathrm{H}$ owever, the inner 29 lamellae of the human aorta do not have vasa vasorum, and the human abdominal aorta lacks vasa vasorum completely (24-26). Consistent with this, therecan bestriking sparing of the media of thehuman aorta even when extensive adventitial inflammation, including germinal center formation, is present (27-29). Even when lymphocytes enter the media of the human great vessels, a segregation of effector cells between layers of the great vessels has been reported, with activated IFN $-\gamma$-secreting T cells being excluded from the media in giant cell arteritis (30). Thus, findings in both the mouse and human are consistent with immunoprivilege of the elastic media based on restricted access of immune effector cells.

While intrinsic properties of the elastic media contributeto in efficient clearance of viral infection, viral factors may also play a role. $\gamma \mathrm{HV} 68$ encodes a secreted protein (M 3) that binds CC chemokines such as RANTES, MCP, and MIP1 $\alpha$, as well as the $C$ and $C X X X C$ chemokines lymphotactin and fractalkine, resulting in failure of chemokine-receptor signaling $(31,32)$. The virus al so encodes the secreted $\gamma \mathrm{H}$ V68 regulator of complement activation (RCA) protein that inhibits both classical and alternative complement activation (33). Expression of $\mathrm{M} 3$ or the $\gamma \mathrm{H} \mathrm{V} 68 \mathrm{RCA}$ protein in the media could influence mononuclear cell infiltration. Notably, the possible contribution of viral factors to arteritis does not invalidate our conclusion that the elastic media of the great vessels is an immunoprivileged site, since $\gamma \mathrm{HV} 68$ is cleared from other organs and other sites in the vasculature despite the contribution of such virulencefactors.

IFN- $\gamma$ action during acute and chronic elastic arteritis and cellular sites of IFN - $\gamma$ action. Together with data presented here for the great vessels, findings in the salivary gland and CNS show that IFN - $\gamma$ is a key determinant of control of persistent virus infection in multiplepathogen and organ systems, especially when persistent infection of an immunoprivileged site is involved (6, 34-39). Since IFN - $\gamma$ determined both the incidence and severity of arteritis, we defined the cellular targets for these actions. IFN $-\gamma$ has effects on somatic cells and, by actions on hematopoietic cells, immune modulatory activities (reviewed in refs. 40 and 41). IFN- $\gamma$ determined theincidence of arteritis by actions on somatic cells since IFN $-\gamma \mathrm{R}^{-1-}$ recipients of wild-type bonemarrow developed arteritis, while wild-type recipients of IFN $-\gamma \mathrm{R}^{-/-}$bone marrow did not. Since studies using transient depletion of IFN $-\gamma$ showed that IFN $-\gamma$ acts early during infection, we conclude that IFN- $\gamma$ action on somatic cells during acute infection determines the incidence of chronic elastic arteritis. Given this, we tested thehypothesis that IFN $-\gamma$ has antiviral effects on primary vascular SMCs. IFN $-\gamma$ significantly protected against $\gamma \mathrm{HV} 68$ infection in both primary SMCs and non-SMCs from mouse aortas. This effect of IFN - $\gamma$ on somatic cells could well contribute to the role of IFN $-\gamma$ in controlling the incidence of chronic el astic arteritis.

Interestingly, the presence of $129 \mathrm{Ev} / \mathrm{Sv}$ derived hematopoietic cells was associated with less severe arteritis in IFN $-\gamma \mathrm{R}^{-1-}$ recipient mice, a finding most consistent with a hematopoietic cell-specific immunoregulatory action of IFN- $\gamma$. Similar to theexperiments pre sented here, IFN $-\gamma$ responsiveness of both somatic and hematopoietic cells is required for resistance to Toxoplasma gondii, which, like $\gamma \mathrm{HV} 68$, invades somatic cells as well as macrophages (42). Thus, regulation of infection by the action of IFN $-\gamma$ on both somatic and hematopoietic cells is a general finding.

Implications. Our results suggest that lesion distribution in chronic vascular disease may result in large part from 

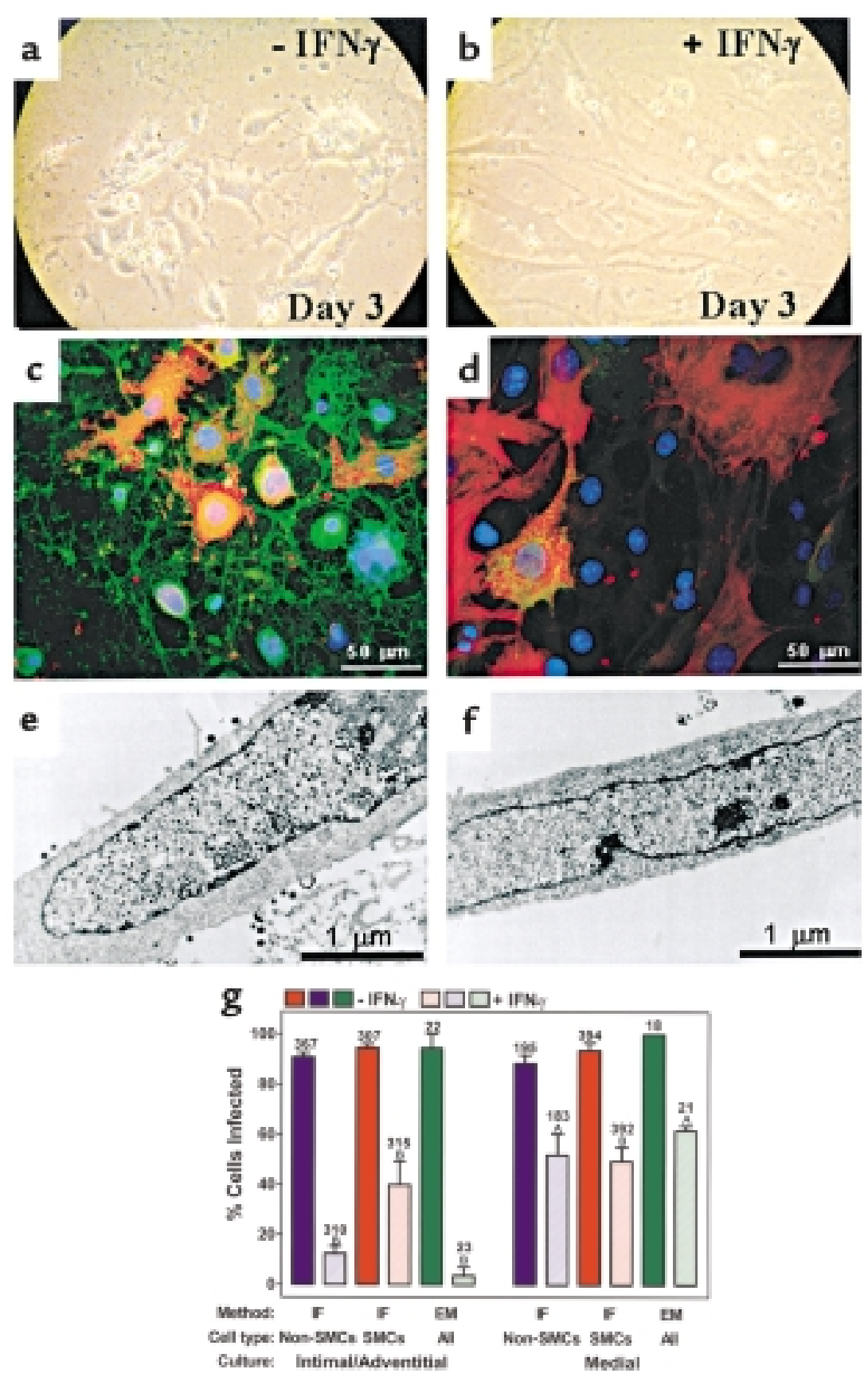

properties intrinsic to different vessels and different layers of the great vessels that prevent efficient immune clearance of foreign or self antigens. Given this, it is clear that strategies for blunting the inflammatory response as a way to control chronic vascular disease may well have a price; continued persistence of the inciting agent or antigen. This may be an especially severe problem for herpesvirus infection since these viruses can go latent and reactivate at a later time to cause disease during immunosuppression. This emphasizes the importance of defin- ing the underlying cause of vascular disease as part of the decision process leading to trials of blockade of immune and inflammatory function in these diseases.

\section{Acknowledgments}

We would like to thank Dr. Bob Schreiber, D r. Wayne Yokoyama, and Dr. Jeff Saffitz for discussions and assistance throughout this project. We also thank members of Dr. David Leib's lab and members of the Speck and Virgin labs for helpful discussions. This work was supported in part by a
Figure 6

IFN $-\gamma$ inhibits $\gamma \mathrm{HV} 68$ infection of primary aortic cells. IFN - $\gamma$-treated and untreated intimal/adventitial and medial cultures were evaluated 3 days after infection. In $\mathbf{c}$ and $\mathbf{d}$ nuclei were stained blue, muscle actin was stained red, and viral antigen was stained green. Uninfected cultures and infected cultures stained with control Ab's demonstrated no viral antigen staining. ( $\mathbf{a}$ and $\mathbf{b}$ ) Phase-contrast microscopy of infected intimal/adventitial cultures with or without IFN $-\gamma$. (c) Representative field of infected medial cultures without IFN - $\gamma$ treatment. (d) Representative field of infected medial cultures treated with IFN $\gamma$. (e) EM of a cell with nuclear capsids from an infected, untreated medial culture. (f) EM of a cell without nuclear capsids from an infected, IFN- $\gamma$-treated medial culture. (g) Multiple fields were evaluated by dual immunofluorescence for viral antigen and muscle actin (three experiments) or by electron microscopy (two experiments). IF, immunofluorescence. The numbers above the bars represent the number of cells counted. For comparing results with or without IFN $-\gamma$ treatment by IF, AP $<0.005$, BP $<0.0002$. For comparing results with or without IFN $-\gamma$ by $E M, A P=0.0024, B P=0.0013$.

research grant from the MonsantoSearle Biomedical Agreement to SHS and by NIH grants CA43143, CA52004 and CA58524 to SHS, and CA74730, HL60090 and Al 39616 to HWV.

1. Weck, K.E., et al. 1997. Murine gammaherpesvirus 68 causes large vessel arteritis in mice lacking interferon-gamma responsiveness: a new model for virus induced vascular disease. $\mathrm{Nat}$ Med. 3:1346-1353

2.Dal Canto, A.J., Virgin, H.W., and Speck, S.H 2000. Ongoing viral replication is required for gammaherpesvirus 68-induced vascular damage. J.Virol. 74:11304-11310.

3. Alber, D.G., Powell, K.L., Vallance, P., Goodwin, D.A., and Grahame-Clarke, C. 2000. Herpesvirus infection accelerates atherosclerosis in the apolipoprotein E-deficient mouse. Circulation. 102:779-785.

4. $\mathrm{N}$ agano, $\mathrm{H}$, et al. 1997. Interferon-gamma deficiency prevents coronary arteriosclerosis but not myocardial rejection in transplanted mouse hearts. J. Clin. Invest. 100:550-557.

5. Gupta, S., et al. 1997. IFN-gamma potentiates atherosclerosis in apoE knock-out mice. J. Clin Invest. 99:2752-2761.

6. Presti, R.M., Pollock, J.L., Dal Canto, A.J., O 'Guin, A.K., and Virgin, H.W. 1998. Interferon-gamma regulates acute and latent murine cytomegal ovirus infection and chronic disease of the great vessels. J. Exp. M ed. 188:577-588.

7. Tellides, G., et al. 2000. Interferon-gamma elicits arteriosclerosis in the absence of leukocytes. Nature 403:207-211.

8.Clambey, E.T., Virgin, H.W., and Speck, S.H 2000. Disruption of the murine gammaherpesvirus $68 \mathrm{M} 1$ open reading frame leads to enhanced reactivation from latency. J. Virol. 74:1973-1984.

9. Van Dyk, L.F., Virgin, H.W., and Speck, S.H. 2000 The murine gammaherpesvirus $68 \mathrm{v}$-cyclin is a 
critical regulator of reactivation from latency. J. Virol. 74:7451-7461.

10. Muller, U., et al. 1994. Functional role of type and type II interferons in antiviral defense. Science. 264:1918-1921.

11. Stabell, E.C., and Olivo, P.D. 1992. Isolation of a cell line for rapid and sensitive histochemical assay for the detection of herpes simplex virus. J. Virol. M ethods. 38:195-204.

12. Virgin, H.W., and Tyler, K.L. 1991. Role of immunecells in protection against and control of reovirus infection in neonatal mice. J. Virol. 65:5157-5164.

13. Austyn, J.M ., and Gordon, S. 1981. F4/80, a monoclonal antibody directed specifically against the mousemacrophage. Eur. J. Immunol. 11:805-815.

14. Huang, S., et al. 1993. Immune response in mice that lack the interferon-gamma receptor. Science. 259:1742-1745.

15. Buchmeier, N.A., and Schreiber, R.D. 1985. Requirement of endogenous interferon-gamma production for resolution of Listeria monocytogenes infection. Proc. Natl. Acad. Sci. USA. 82:7404-7408

16. Heise, M.T., and Virgin, H.W. 1995. The T cel independent role of IFN-gamma and TNF-alpha in macrophage activation during murine cytomegalovirus and herpes simplex virus infection. J. Virol. 69:904-909.

17. Ramos, K.S., and Cox, L.R. 1993. Aortic endothe lial and smooth musclecell cultures. In M ethodsin toxicology. A. Tyson and J.M . Frazier, editors. Academic Press. N ew York, N ew York, USA. 159-168.

18. Gunther, S., Alexander, R.W., Atkinson, W.J., and Gimbrone, M .A.J. 1982. Functional angiotensin II receptors in cultured vascular smooth muscle cells. J. Cell. Biol. 92:289-298.

19. Hart, M.N., Tassell, S.K., Sadewasser, K.L., Schelper, R.L., and Moore, S.A. 1985. Autoimmune vasculitis resulting from in vitro immunization of lymphocytes to smooth muscle. Am. J. Pathol. 119:448-455.

20. Ahmed, R., Morrison, L.A., and Knipe, D.M 1996. Persistence of viruses. In Fields virology. B.N. Fields, D.M . Knipe, and P.M . Howley, editors. Lippincott-Raven. Philadel phia, Pennsylvania, USA
219-249.

21. Ando, K., Guidotti, L.G., Cerny, A., Ishikawa, T., and Chisari, F.V. 1994. CTL access to tissue antigen is restricted in vivo. J. Immunol. 153:482-488.

22. Galis, Z.S., Sukhova, G.K., Lark, M.W., and Libby, P. 1994. Increased expression of matrix metalloproteinases and matrix degrading activity in vulnerable regions of human atherosclerotic plaques. J. Clin. Invest. 94:2493-2503.

23. Galis, Z.S., et al. 1994. Cytokinestimulated human vascular smooth muscle cells synthesize a complement of enzymes required for extracellular matrix digestion. Circ. Res. 75:181-189.

24. Wolinsky, H., and Glagov, S. 1967. A lamellar unit of aortic medial structure and function in mammals. Circ. Res, 20:99-111.

25. Wolinsky, H., and Glagov, S. 1967. Nature of species differences in the medial distribution of aortic vasa vasorum in mammals. Circ. Res 20:409-421.

26. Wolinsky, H., and Glagov, S. 1969. Comparison of abdominal and thoracic aortic medial structure in mammals. Deviation of man from the usual pattern. Circ. Res. 25:677-686.

27. Ramshaw, A.L., and Parums, D.V. 1990 Immunohistochemical characterization of inflammatory cells associated with advanced atherosclerosis. Histopathology. 17:543-552.

28. Parums, D.V., Dunn, D.C., Dixon, A.K., and Mitchinson, M.J. 1990. Characterization of inflammatory cells in a patient with chronic periaortitis. Am. J. Cardiovasc. Pathol. 3:121-129.

29. Parums, D.V. 1990. The spectrum of chronic periaortitis. Histopathology. 16:423-431.

30.Wagner, A.D., Bjornsson, J., Bartley, G.B., Goronzy, J.J., and Weyand, C.M . 1996. Interferongamma-producing $T$ cells in giant cell vasculitis represent a minority of tissue-infiltrating cells and are located distant from the site of pathology. Am. J. Pathol. 148:1925-1933.

31. Parry, B.C., et al. 2000. A broad spectrum secreted chemokinebinding protein encoded by a herpesvirus. J. Exp. Med. 191:573-578.

32. van Berkel, V., et al. 2000. Identification of a gammaherpesvirus selective chemokine binding protein that inhibits chemokine action. J. Virol.
74:6741-6747.

33. Kapadia, S.B., M olina, H., van Berkel, V., Speck, S.H., and Virgin, H.W. 1999. M urine gammaherpesvirus 68 encodes a functional regulator of complement activation. J. Virol. 73:7658-7670

34. Jonjic, S., Pavic, L., Lucin, P., Rukavina, D ., and Koszinowski, U.H. 1990. Efficacious control of cytomegalovirus infection after long-term depletion of CD8+ T lymphocytes. J. Virol. 64:5457-5464.

35.Jonjic, S., M utter, W., Weiland, F., Reddehase M.J., and Koszinowski, U.H. 1989. Siterestricted persistent cytomegalovirus infection after selectivelong-term depletion of CD 4+T lymphocytes J. Exp. Med. 169:1199-1212.

36. Lucin, P., Pavic, I., Polic, B., Jonjic, S., and Koszinowski, U.H. 1992. Gamma interferon-dependent clearance of cytomegalovirus infection in salivary glands. J. Virol. 66:1977-1984.

37. Tishon, A., Lewicki, $H$, Rall, G., Von Herath, M and Oldstone, M.B.A. 1995. An essential rolefor type 1 interferon-gamma in terminating persistent viral infection. Virology. 212:244-250.

38. von Herrath, M.G., Coon, B., and Oldstone, M .B. 1997. Low-affinity cytotoxic T-lymphocytes require IFN-gamma to clear an acute viral infection. Virology. 229:349-359.

39. Planz, O., et al. 1997. A critical role for neutralizing-antibody-producing B cells, CD 4(+) T cells, and interferons in persistent and acute infections of mice with lymphocytic choriomeningitis virus: implications for adoptiveimmunotherapy of virus carriers. Proc. Natl. Acad. Sci. USA. 94:6874-6879.

40. Biron, C. 1994. Cytokines in the generation of immune responses to, and resolution of, virus infection. Curr. Opin. Immunol. 6:530-538.

41.Stark, G.R., Kerr, I.M., Williams, B.R., Silverman, R.H., and Schreiber, R.D. 1998. How cells respond to interferons. Annu. Rev. Biochem. 67:227-264.

42. Yap, G.S., and Sher, A. 1999. Effector cells of both nonhemopoietic and hemopoietic origin are required for interferon (IFN)-gamma- and tumor necrosis factor (TNF)- alpha-dependent host resistanceto theintracellular pathogen, Toxoplasma gondii. J. Exp. M ed. 189:1083-1092. 